\title{
Microarc surface alloying of tool steels
}

\author{
Makar S. Stepanov*, Yuri M. Dombrovskii, and Levon V. Davidyan \\ Don State Technical University, Physical and Applied Materials Science Department, 344000 \\ Rostov-on-Don, Russia
}

\begin{abstract}
A new method of accelerating of steel diffusion saturation during thermo-chemical treatment - microarc surface alloying is proposed. The steel product is placed in a metal container filled with coal powder, and heated by passing an electric current. Powder having microarcs, which are concentrated around the surface of the product with the formation of zones of local gas discharge. This significantly speeds up the diffusion saturation. After carburizing of steel $20 \mathrm{Cr} 13$ is formed a diffusion layer thickness of 13-15 $\mu \mathrm{m}$ microhardness of 10.5 to $12.5 \mathrm{HPa}$, located below the eutectoid area a thickness of $300 \mu \mathrm{m}$ and a hardness of 6.5 GPA. After boriding of steel $\mathrm{Cr} 12 \mathrm{~V} 1$ after standard heat treatment, the surface layer with a thickness of 170-180 $\mu \mathrm{m}$ consists of a base with microhardness of 9.3-9.6 GPA with inclusions of microhardness of 14.5-15.0 GPA. After boriding of steel $5 \mathrm{CrNiMo}$ formed a layer thickness of $250-260 \mu \mathrm{m}$ with a composite structure consisting of sections of the eutectoid structure of microhardness of 7.0-8.0 GPA, surrounded by boride eutectic microhardness 12.0-12.5 GPA. The composite structure provides the combination of very hard boride eutectic and eutectoid plastic mixture. After boriding of steel W6Mo5Co5 after standard heat treatment, the surface layer thickness of $230-240 \mu \mathrm{m}$ consists of a base of microhardness 11,0-11,2 GPA with inclusions of microhardness 13,5-14,5 GPA. Given the high intensity of diffusion saturation, microarc surface alloying is recommended for surface hardening of tool steels.
\end{abstract}

\section{Introduction}

Traditional processes of thermo-chemical treatment of steel products are characterized by a long duration [1], so now new methods of intensification of diffusion surface saturation based on the use of high-speed electric heating are proposed. One of them is microarc thermo-chemical treatment $[2,3]$. The steel product is placed in a metal container filled with coal powder, after which an electric current is passed in the source - container powder environment - steel product. When the current flows in the powder environment, microarc discharges occur, which concentrate around the surface of the processed product to form a zone of local gas discharge, which can significantly intensify the diffusion saturation process [4-6]. Pyrolysis of coal as a result of its heating leads to the formation of a carbon-containing atmosphere, which protects the product from oxidation, and is a source of carbon that can diffuse into the surface layer. Therefore, a feature of the process is that it

\footnotetext{
*Corresponding author: stepanovms@yandex.ru
} 
is always accompanied by carbonizing steel products. In addition, it is possible to form carbide-type coatings, for which the surface of the product is pre-coated with a coating containing carbide-forming elements (chromium, molybdenum, vanadium, tungsten) [7-9]. Carbide-type coating is formed by simultaneous diffusion of carbon and carbide-forming metal. When using coatings containing boron compounds, formation of boride coatings is possible [10].

In previous works investigated the physical phenomena under the influence of microarcs on the surface of the steel samples and proposed a physical theory of the acceleration of diffusion by the action of microarc discharges.

Earlier studies were limited to the study of microarc surface saturation of low-carbon structural steel, and the creation of diffusion coatings on the surface of alloyed tool steels was not considered.

The aim of this work was to study the possibility of using microarc diffusion saturation of the surface layer of alloyed tool steels.

\section{Methods of study}

In the experiments we used the equipment for microarc alloying [2]. Cylindrical samples with a diameter of $12 \mathrm{~mm}$ and a length of $35 \mathrm{~mm}$ was immersed to the half of the length in a metal container filled with powder of coal (anthracite) with a particle size of 0.4-0.6 mm, and was heated by passing an electric current in a circuit power source container - powder environment - sample.

For carburizing, the samples were loaded into the coal powder. For the formation of carbide type coatings on the samples surface was applied a chemical containing ferrochromium, ferromolybdenum, ferrovanadium, and ferrotungsten [7-9]. To boron the surface of the samples, a coating containing amorphous boron was previously applied [10].

The surface current density was $0.53 \mathrm{~A} / \mathrm{cm}^{2}$. The temperature of the process increased from room to $1250^{\circ} \mathrm{C}$, and then stabilized at this level [6]. The total duration of the process was 3 minutes.

Transverse sections of the samples were examined using a microscope Neophot-21. The microhardness of the coatings was measured at loads on the indenter of $0.49 \mathrm{~N}$ and $0.196 \mathrm{~N}$.

For research, samples were taken from corrosion-resistant steel 20 Cr13, die steels for cold deformation and hot deformation Cr12V1 5CrNiMo, and high-speed steel W6Mo5Co5.

\section{Results and discussion}

Cementation of samples from steel $20 \mathrm{Cr} 13$ in the mode of microarc heating leads to the appearance of a diffusion layer 13-15 microns thick, under which the eutectoid structure zone of the order of 300 microns thick is located. The microhardness of the layer is 10.5-12.5 GPA, which corresponds to the microhardness of chromium carbides, and the eutectoid zone is 6.5 GPA. Next is the original structure of steel $20 \mathrm{Cr} 13$ microhardness 5.8-6.5 GPA (Fig. 1).

After microarc boriding of steel Cr12V1 occurs surface layer thickness 170-180 $\mu \mathrm{m}$, consisting of a base a hardness of 9.3 and 9.6 GPA, with light inclusions microhardness of 14.5 to 15.0 GPA (Fig. 2). This is followed by the structure of steel Cr12V1 after standard heat treatment with an integral hardness of 8.0-9.0 GPA.

On the surface of steel $5 \mathrm{CrNiMo}$ after microarc boriding formed the layer thickness 250-260 $\mu \mathrm{m}$ with a composite structure consisting of areas of eutectoid mixture of a 
hardness of 7.0-8.0 GPA, surrounded by layers of boride eutectic with microhardness 12,012,5 $\mathrm{HPa}$ (Fig. 3).

The presence of boride eutectic along the borders is explained by the predominance of grain boundary diffusion of boron and carbon over the transcrystalline, with double eutectic $\mathrm{Fe}-\mathrm{B}$ formed at a temperature of $1177^{\circ} \mathrm{C}$ at a boron concentration of $17 \%$, and triple $-\mathrm{Fe}-$ $\mathrm{C}$-B-at $1100^{\circ} \mathrm{C}$ and concentrations of $2.9 \% \mathrm{~B}$ and $1.5 \% \mathrm{C}$. The composite structure of the boron layer is more preferable than the structure after traditional boration, because it contains a combination of high-solid component-boride eutectic, and relatively plastic eutectic mixture.



Fig. 1. The microstructure of the surface layer of steel $20 \mathrm{Cr} 13$ after microarc carburizing.

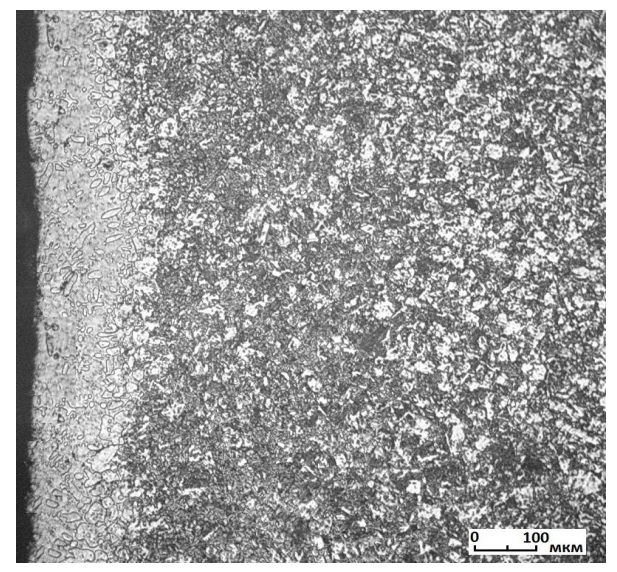

Fig. 2. The microstructure of the surface layer of steel Cr12V1 after microarc boriding.

Microarc boriding samples of W6Mo5Co5 steel after the standard heat treatment led to the formation of the surface layer with a thickness of 230 to $240 \mu \mathrm{m}$, consisting of a base microhardness of 11.0 to 11.2 GPA, with light inclusions microhardness of 13.5 to 14.5 GPA (Fig. 4). Next is the area with the original structure characteristic of steel W6Mo5Co5 after heat treatment with an integral hardness of 9.3-9.6 GPA.

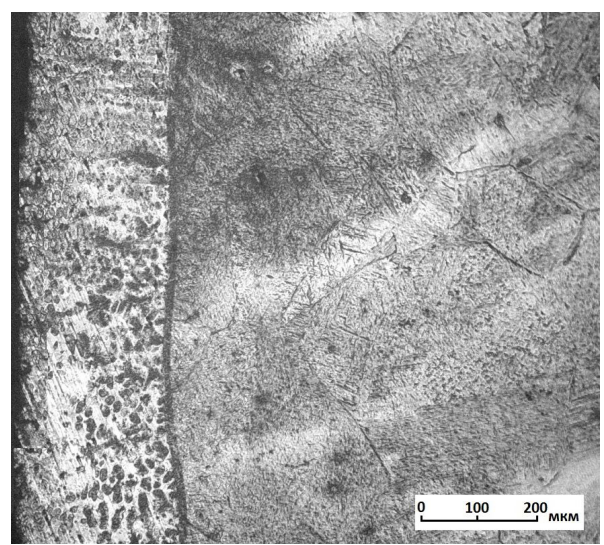

Fig. 3. The microstructure of the surface layer of steel $5 \mathrm{CrNiMo}$ after microarc boriding.

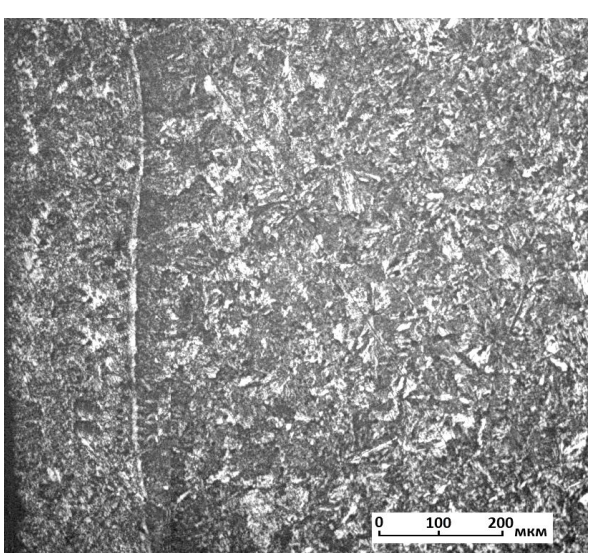

Fig. 4. The microstructure of the surface layer of steel W6Mo5Co5 after microarc boriding. 
The composition structure of the boriding layer is more preferable than the structure after traditional boration, as it contains a combination of a high - solid component-boride eutectic, and a relatively plastic eutectoid mixture.

The results obtained allow us to conclude that in alloyed steels containing carbideforming elements $(\mathrm{Cr}, \mathrm{Mo}, \mathrm{V}, \mathrm{W})$ in their composition, the formation of carbide-type hardening phases in the surface layer can be achieved only by carburizing, which is typical for all microarc alloying processes. In addition, to obtain even more hard coatings, it is advisable to saturate such steels with carbon and boron.

Given the high intensity of diffusion saturation, microarc surface alloying is recommended for tool steels surface hardening.

\section{Conclusions}

1. Microarc surface saturation of tool steels with carbon or together with carbon and boron allows to obtain a hardened layer consisting of phases of carbide type and boride double or triple (with carbon) eutectic thickness up to $300 \mu \mathrm{m}$ microhardness up to $15 \mathrm{GPA}$, which will enhance the durability of the die and metal-cutting tool.

2. For low-carbon steels containing a carbide-forming element (20Cr13), microarc cementation is sufficient.

3. In medium-carbon tool steels ( $5 \mathrm{CrNiMo}$ ) hardening is achieved by microarc boriding to form a composite structure consisting of sections of eutectoid mixture surrounded by a layer of boride eutectic.

4. In high-alloy die and high-speed steels (Cr12V1, W6Mo5Co), microarc boron saturation leads to the formation of carbide and boride phases in the surface layer with the participation of alloying elements from the composition of these steels.

\section{References}

1. L.G. Voroshnin, Theory and technology of thermo-chemical treatment (Novoe znanie, Moscow, 2010)

2. M.S. Stepanov, Y.M. Dombrovskii, V.N. Pustovoit, Metal Science and Heat Treatment, 59 (1-2), 55 (2017)

3. M.S. Stepanov, Yu.M. Dombrovskii, V.N. Pustovoit, Metal Science and Heat Treatment, 59 (5-6), 308 (2017)

4. M.S. Stepanov, Yu.M. Dombrovskii, Y.A. Kornilov, Strengthening technologies and coatings, 8, 34 (2016)

5. M.S. Stepanov, Yu.M. Dombrovskii, Physics and chemistry of materials treatment, 1, 5 (2017)

6. M.S. Stepanov, Yu.M. Dombrovskii, Y.A. Kornilov, Zavodskaya Laboratoriya. Diagnostika Materialov, 82 (3), 42 (2016)

7. Yu.M. Dombrovskii, M.S. Stepanov, Izvestiya Vysshikh Uchebnykh Zavedenij. Chernaya Metallurgiya, 60 (4), 262 (2017)

8. M.S. Stepanov, Yu.M. Dombrovskii, Steel in Translation, 46 (2), 79 (2016)

9. M.S. Stepanov, Yu.M. Dombrovskii, Inorganic Materials: Applied Research, 9 (4), 703 (2018)

10. Yu.M. Dombrovskii, M.S. Stepanov, Izvestiya Vysshikh Uchebnykh Zavedenij. Chernaya Metallurgiya, 58 (3), 214 (2015) 